\title{
Protonation Preferentially Stabilizes Minor Tautomers of the Halouracils: IRMPD Action Spectroscopy and Theoretical Studies
}

\author{
K. T. Crampton, ${ }^{1}$ A. I. Rathur, ${ }^{1}$ Y.-w. Nei, ${ }^{1}$ G. Berden, ${ }^{2}$ J. Oomens,,${ }^{2,3}$ M. T. Rodgers ${ }^{1}$ \\ ${ }^{1}$ Department of Chemistry, Wayne State University, Detroit, MI, 48202, USA \\ ${ }^{2}$ FOM Institute for Plasma Physics Rijnhuizen, Edisonbaan 14, 3439 MN, Nieuwegein, The Netherlands \\ ${ }^{3}$ van't Hoff Institute for Molecular Sciences, University of Amsterdam, Science Park 904, 1098 XH, Amsterdam, \\ The Netherlands
}

\begin{abstract}
Tautomerization induced by protonation of halouracils may increase their efficacy as anti-cancer drugs by altering their reactivity and hydrogen bonding characteristics, potentially inducing errors during DNA and RNA replication. The gas-phase structures of protonated complexes of five halouracils, including 5-fluorouracil, 5-chlorouracil, 5-bromouracil, 5-iodouracil, and 6-chlorouracil are examined via infrared multiple photon dissociation (IRMPD) action spectroscopy and theoretical electronic structure calculations. IRMPD action spectra were measured for each complex in the IR fingerprint region extending from $\sim 1000$ to $1900 \mathrm{~cm}^{-1}$ using the free electron laser (FELIX). Correlations are made between the measured IRMPD action spectra and the linear IR spectra for the stable low-energy tautomeric conformations computed at the B3LYP/ $6-311+G(2 d, 2 p) / / B 3 L Y P / 6-31 G^{*}$ level of theory. Absence of an intense band(s) in the IRMPD spectrum arising from the carbonyl stretch(es) that are expected to appear near $1825 \mathrm{~cm}^{-1}$ provides evidence that protonation induces tautomerization and preferentially stabilizes alternative, noncanonical tautomers of these halouracils where both keto functionalities are converted to hydroxyl groups upon binding of a proton. The weak, but measurable absorption, which does occur for these systems near $1835 \mathrm{~cm}^{-1}$ suggests that in addition to the groundstate conformer, very minor populations of excited, low-energy conformers that contain keto functionalities are also present in these experiments.
\end{abstract}

Key words: 5-Bromouracil, 5-Chlorouracil, 6-Chlorouracil, 5-Fluorouracil, Free electron laser, Infrared multiple photon dissociation, 5-lodouracil, Protons, Tautomerization

\section{Introduction}

$\mathrm{T}$ he preservation of genetic material in biological systems has long been known to be due to the specificity of Watson-Crick base pairing of nucleic acids. Consequently,

Electronic supplementary material The online version of this article (doi:10.1007/s13361-012-0434-7) contains supplementary material, which is available to authorized users.

Correspondence to: M. T. Rodgers; e-mail: mrodgers@chem.wayne.edu genetic mutations have been hypothesized to arise as a result of deviations from the complementarities of base pairing in DNA and RNA [1-5]. Many scientists have proposed that the presence of rare, noncanonical tautomers of the purine and pyrimidine nucleobases account for these mutations [1, 5-9]. Such tautomerization of these nucleobase moieties reverses the polarity of hydrogen bonding sites, causing incorrect base pairing during nucleic acid synthesis [10], again, leading to mutations in an organism's genome and possibly carcinogenesis [1114]. The structures and relative stabilities of the various 
tautomers of uracil have been extensively investigated [15-26]. Although the canonical form of uracil lacks aromaticity, it is still stable because it can undergo amide-imide tautomerization [27]. While the noncanonical tautomers of uracil all lie higher in energy than the canonical form, these high-energy conformers can be stabilized via protonation [10]. This phenomenon has been experimentally confirmed for thioketo- and methythioketouracils as well [15]. According to the theories of Watson and Crick [1] and based on recent work of Salpin et al. [10], minor tautomers of uracil stabilized by protonation and incorporated into RNA to make noncanonical base pairs could be used to induce mutations in RNA. The 5- and 6-halouracils are already known for an array of pharmaceutical properties, most notably 5-fluorouracil (5FU), which is in many cases the first-line chemotherapeutic agent used for colorectal and pancreatic cancer [28-32]. While the main mechanism of action of $5 \mathrm{FU}$ is to inhibit the conversion of uracil to thymine [31], a nucleobase used in DNA synthesis, it can also be directly incorporated into RNA to prevent gene expression, even after replication has successfully occurred. In this minor mechanism of action, 5FU would form hydrogen bonds with adenine, but if tautomeric shifts occur, base pairing may occur with other bases; in either case, a mutation will be induced, resulting in the eventual death of the cancerous cell. Research has shown measurable incorporation of 5FU in RNA, and to a lesser extent in DNA, but no correlation was found between its incorporation and therapeutic efficacy [32, 33]. If the noncanonical tautomers of $5 \mathrm{FU}$ could be stabilized, this could increase its ability to form nonstandard base pairs, possibly increasing its efficacy as an anticancer drug via the minor mechanism of action. This study aims to determine if protonation stabilizes noncanonical tautomers of the halouracils in the same fashion as found for thioketo- and methylthioketouracils [15].

In the present work, the interactions of a series of halouracils, $x \mathrm{U}$ including: 5FU, 5-chlorouracil (5ClU), 5-bromouracil (5BrU), 5-iodouracil (5IU), and 6-chlorouracil (6ClU), with protons are examined. Electronic structure calculations are performed at the B3LYP/6-311+G(2d,2p)//B3LYP/6-31G* level of theory to determine the structures, relative stabilities, and linear IR spectra of the ground-state and low-energy tautomeric forms of the halouracils. The computed linear IR spectra are compared with the spectra measured using infrared multiple photon dissociation (IRMPD) action spectroscopy of these species to determine the tautomeric conformations accessed in the experiments. This synergistic experimental and theoretical investigation allows for determination of the structures, reactivity, relative stability, and IR active vibrations of the protonated halouracils. IRMPD action spectroscopy experiments combined with theoretical calculations have become increasingly employed for the structural charac- terization of a wide variety of ionic species $[15,17,34-$ 40]. In particular, this approach enables the identification and differentiation of the various stable tautomers of the nucleobases, including simple rotamers in favorable cases $[15,17]$.

\section{Experimental and Computational}

\section{Mass Spectrometry and Photodissociation}

IRMPD action spectra of five protonated halouracils, $\mathrm{H}^{+}(x \mathrm{U})$, were measured using a $4.7 \mathrm{~T}$ Fourier transform ion cyclotron resonance mass spectrometer (FT-ICR MS) that has been described in detail elsewhere [34-38]. This FT-ICR MS is coupled to the free electron laser (FELIX), which provides the tunable infrared radiation required to accomplish photodissociation in these experiments [34]. The nucleobases, 5FU and 5BrU, were purchased from Sigma-Aldrich, (Zwijndrecht, Netherlands) while $5 \mathrm{ClU}, 6 \mathrm{ClU}$, and $5 \mathrm{IU}$ were purchased from TCI Europe, (Zwijndrecht, Belgium). Protonated complexes of the nucleobases studied here were formed using an electrospray ionization (ESI) source (Micromass Z-spray) from solutions containing $1.6 \mathrm{mM}$ halouracil and $2.4 \mathrm{mM}$ trifluoroacetic acid in an approximately $50 \%: 50 \% \mathrm{MeOH}: \mathrm{H}_{2} \mathrm{O}$ mixture. Solutions were sprayed at a flow rate of $10 \mu \mathrm{L} / \mathrm{min}$ and the electrospray needle was generally held at a voltage of $\sim 3.3 \mathrm{kV}$. Gas phase ions generated by the ESI source were accumulated in a hexapole ion trap for $\sim 4.5$ to $5 \mathrm{~s}$ before being pulseextracted into a quadrupole bender, and subsequently injected into the ICR cell via an $\mathrm{rf}$ octopole ion guide. Collisional heating of the ions resulting from traditional ion capturing methods such as introduction of a gas pulse is avoided through implementation of a "DC bias switch" allowing for simple gated trapping in the ICR cell as previously described [35]. Stored waveform inverse Fourier transform (SWIFT) techniques are employed for mass selection of precursor ions. Once isolated, precursor ions were irradiated with infrared radiation from the FEL at pulse energies of $\sim 40 \mathrm{~mJ}$ per macropulse of $5 \mu \mathrm{s}$ duration at a repetition rate of $10 \mathrm{~Hz}$. Ions were allowed to interact with the FEL for $3 \mathrm{~s}$, allowing 30 macropulses to interact with the ions over the wavelength range from $10.2 \mu \mathrm{m}\left(\sim 1000 \mathrm{~cm}^{-1}\right)$ to $5.2 \mu \mathrm{m}\left(\sim 1900 \mathrm{~cm}^{-1}\right)$. The IRMPD yield was computed using the fragment $\left(I_{f_{i}}\right)$ and precursor ion intensities $\left(I_{p}\right)$ at each frequency after laser irradiation as shown in equation 1.

$$
\operatorname{IRMPD} \text { Yield }=\sum_{i} I_{f_{i}} /\left(I_{p}+\sum_{i} I_{f_{i}}\right)
$$

Linear power corrections were made to all spectra to account for variations in the output of the FEL as a function of laser wavelength. As the FEL outputs less power at short 
wavelengths, these corrections result in an increase in relative peak intensities in the high energy region of the spectra as previously shown $[39,40]$.

\section{Computational Details}

Tautomers of neutral and protonated halouracils, 5FU, $5 \mathrm{ClU}$, $5 \mathrm{BrU}, 5 \mathrm{IU}$, and $6 \mathrm{ClU}$ were constructed using GaussView software. All plausible low-energy tautomeric forms were carefully considered. Geometry optimizations were performed at the B3LYP/6-31G* level of theory using Gaussian 09 [41]. Single point energy calculations at the B3LYP/6$311+\mathrm{G}(2 \mathrm{~d}, 2 \mathrm{p})$ level of theory, along with zero-point energy and thermal corrections determined at the B3LYP/6-31G* level of theory, were used to determine the relative enthalpies at 0 and $298 \mathrm{~K}$ and Gibbs free energies at $298 \mathrm{~K}$ for all stable geometries found. Calculated infrared intensities and harmonic vibrational frequencies (scaled by a factor of 0.96) were used to generate theoretical linear IR spectra that were then convoluted with a $20 \mathrm{~cm}^{-1}$ FWHM Gaussian line shape.

\section{Results}

\section{IRMPD Action Spectroscopy}

IRMPD action spectra were measured for five $\mathrm{H}^{+}(x \mathrm{U})$ complexes over the range extending from $\sim 1000$ to $1900 \mathrm{~cm}^{-1}$, and are presented in Figure 1 along with the IRMPD action spectrum of protonated uracil, $\mathrm{H}^{+}(\mathrm{U})$, previously reported by our group [15]. Two independent dissociation pathways were observed upon photodissociation of the protonated halouracils. Loss of $\mathrm{NH}_{3}$ was observed as the primary dissociation channel, while loss of $\mathrm{CONH}$ was also observed as a minor fragmentation pathway.

The key spectral features exhibited by $\mathrm{H}^{+}(\mathrm{U})$ are preserved for the $\mathrm{H}^{+}(x \mathrm{U})$ systems, which suggests that these species exhibit similar binding interactions. However, distinctions exist in these spectra that allow them to be differentiated amongst themselves and from $\mathrm{H}^{+}(\mathrm{U})$. The absence of an intense carbonyl stretch near $1825 \mathrm{~cm}^{-1}$ for the $\mathrm{H}^{+}(x \mathrm{U})$ complexes suggests that protonation preferentially stabilizes an alternative, noncanonical tautomer of these nucleobases where both keto functionalities are converted to hydroxyl groups upon the binding of a proton. The IRMPD spectrum of $\mathrm{H}^{+}(5 \mathrm{FU})$ exhibits greater complexity than that of $\mathrm{H}^{+}(\mathrm{U})$. Absorption bands in the range from $\sim 1070$ to $1290 \mathrm{~cm}^{-1}$ and $\sim 1470$ to $1670 \mathrm{~cm}^{-1}$ are severely broadened and poorly resolved. As compared to $\mathrm{H}^{+}(\mathrm{U})$, the absorption band at $\sim 1376 \mathrm{~cm}^{-1}$ is quite noticeably blue shifted. In contrast, the IRMPD spectrum of $\mathrm{H}^{+}(5 \mathrm{ClU})$ looks similar to the spectrum of $\mathrm{H}^{+}(\mathrm{U})$. However, most features become more intense relative to the carbonyl stretch. Slightly better resolution is observed for the absorption bands in the region from $\sim 1070$ to $1325 \mathrm{~cm}^{-1}$. These spectral features are slightly blue shifted as is the absorption band near $\sim 1375 \mathrm{~cm}^{-1}$. Similar behavior is observed for $\mathrm{H}^{+}(5 \mathrm{BrU})$ and $\mathrm{H}^{+}(5 \mathrm{IU})$. The spectral feature in the region

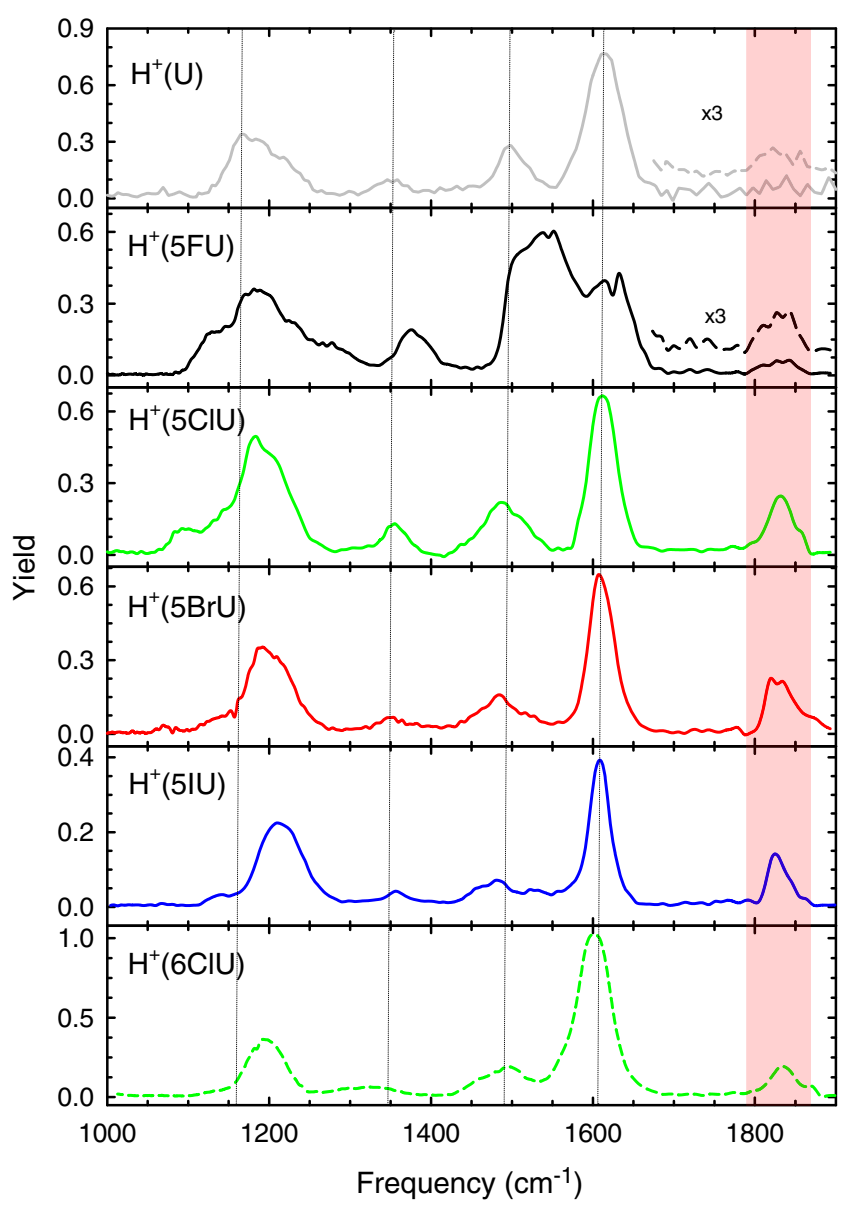

Figure 1. Infrared multiple photon dissociation action spectra of $\mathrm{H}^{+}(\mathrm{U})$ and $\mathrm{H}^{+}(x \mathrm{U})$ complexes

near $1600 \mathrm{~cm}^{-1}$ continues to red shift and becomes narrower as the size of the halogen substituent increases. The blue shift occurring in the region from $\sim 1100$ to $1250 \mathrm{~cm}^{-1}$ for $\mathrm{H}^{+}(5 \mathrm{ClU})$ is also observed for $\mathrm{H}^{+}(5 \mathrm{BrU})$ and $\mathrm{H}^{+}(5 \mathrm{IU})$ with the magnitude of the shift increasing with the size of the halogen substituent. Interestingly, the spectrum for $\mathrm{H}^{+}(6 \mathrm{ClU})$ does not exhibit an absorption band near $\sim 1350 \mathrm{~cm}^{-1}$. This difference in the IRMPD spectrum allows the site of halogenation to be easily determined for these complexes. Relative to $\mathrm{H}^{+}(\mathrm{U})$, the features for $\mathrm{H}^{+}(6 \mathrm{ClU})$ in the region $\sim 1425$ to $1650 \mathrm{~cm}^{-1}$ are red shifted and slightly less resolved. In the $\mathrm{H}^{+}(x \mathrm{U})$ complexes, absorption in the region from $\sim 1150$ to $1250 \mathrm{~cm}^{-1}$ appears to be due to multiple overlapping vibrational modes. This does not appear to be the case for $\mathrm{H}^{+}(6 \mathrm{ClU})$ as absorption in this region gives rise to a single, distinct, relatively broad band near $\sim 1200 \mathrm{~cm}^{-1}$.

\section{Theoretical Results}

The six most stable tautomers of uracil and the halouracils, determined at the B3LYP/6-311+G(2d,2p)//B3LYP/6-31G* level of theory, are shown in Figure 2. Including all possible rotamers of each tautomeric form, there are a total of 13 possible stable conformers that lie within $\sim 100 \mathrm{~kJ} / \mathrm{mol}$ of the ground-state tautomeric conformation for each halouracil. 
<smiles>[X]c1c([Y])n([TlH])c(=O)[nH]c1=O</smiles>

a<smiles>[X]c1[nH]c(=O)nc(O)c1[X]</smiles>

d<smiles>[X]c1nc(O)[nH]c(=O)c1[X]</smiles>

b<smiles>[X]c1c([Y])n([TlH])c(O)nc1=O</smiles>

e<smiles>[X]c1nc(O)nc(O)c1[X]</smiles>

C<smiles>[X]C/C=C(/C[2H])O[2H]</smiles><smiles>[Y]c1[nH]c(=O)[nH]c(=O)c1[X]</smiles>

J<smiles></smiles>

B<smiles>[Y]c1[nH]c(=O)[nH]c(=O)c1[X]</smiles>

E<smiles></smiles>

$\mathrm{H}$<smiles>[Y]c1nc(O)[nH]c(=O)c1[X]</smiles>

K<smiles>[Y]c1nc(O)[nH]c(=O)c1[X]</smiles><smiles></smiles>

F<smiles>[Y]c1nc(O)[nH]c(=O)c1[X]</smiles>

I<smiles>[Y]c1[nH]c(=O)[nH]c(=O)c1[X]</smiles><smiles>[Y]c1nc(O)[nH]c(=O)c1[X]</smiles>

The geometry-optimized structures of all of these tautomeric five halouracils are included in Figure S1 of the Supplementary Information. The canonical a tautomer was found to be the lowest energy structure for all of the neutral halouracils. The next most stable tautomers lie $34.5-40.6 \mathrm{~kJ} /$ mol higher in free energy at $298 \mathrm{~K}$. As found in previous IRMPD work [15] and threshold collision-induced dissociation (TCID) experiments [16], protonation of the canonical tautomer, a, occurs preferentially at the $\mathrm{O} 4$ position rather than the at the N1, O2, or N3 positions. However, the O4 protonated canonical tautomer is not the ground-state conformer.

The 12 most stable tautomeric forms of protonated uracil, $\mathrm{H}^{+}(\mathrm{U})$, and the protonated halouracils, $\mathrm{H}^{+}(5 \mathrm{FU}), \mathrm{H}^{+}(5 \mathrm{ClU})$, $\mathrm{H}^{+}(5 \mathrm{BrU}), \mathrm{H}^{+}(5 \mathrm{IU})$, and $\mathrm{H}^{+}(6 \mathrm{ClU})$, based on theoretical calculations at the B3LYP/6-311+G(2d,2p)//B3LYP/6-31G* level of theory, are shown in Figure 3. Enthalpies at 0 and $298 \mathrm{~K}$ and Gibbs free energies at $298 \mathrm{~K}$ relative to the most stable conformer for all five protonated halouracils are listed in Table S1 of the Supplementary Information. In each case, the ground-state is conformer $\mathbf{A}$ in which hydrogen atoms are bound to the $\mathrm{N} 1, \mathrm{O} 2$, and $\mathrm{O} 4$ atoms, and the $\mathrm{O} 2$ and $\mathrm{O} 4$ hydrogen atoms are oriented towards the adjacent $\mathrm{N} 3$ atom. In comparison with the neutral halouracil tautomers shown in Figure 2, this low-energy conformer is formed from proton binding to $\mathbf{c}$, d, or e, which lie $44.9-49.8 \mathrm{~kJ} / \mathrm{mol}$, $38.1-48.1 \mathrm{~kJ} / \mathrm{mol}$, and $66.8-76.2 \mathrm{~kJ} / \mathrm{mol}$ higher in free energy than the ground-state canonical a tautomers, respectively. Conformer $\mathbf{A}$ can also be formed from a upon protonation at the $\mathrm{O} 4$ or $\mathrm{O} 2$ position with concomitant
Figure 3. Structures of the 12 most stable conformers of protonated uracil, $\mathrm{H}^{+}(\mathrm{U})$, and the protonated halouracils where $X=\mathrm{H}, \mathrm{F}, \mathrm{Cl}, \mathrm{Br}$, or I and $\mathrm{Y}=\mathrm{H}$, or $X=\mathrm{H}$ and $\mathrm{Y}=\mathrm{Cl}$, based on theoretical calculations at the B3LYP/6-311+G $(2 d, 2 p) / / B 3 L Y P / 6-31 G(d)$ level of theory

proton transfer from $\mathrm{N} 3$ to $\mathrm{O} 2$ or $\mathrm{O} 4$, respectively, which may be catalyzed by acid or solvent in the ESI of these systems.

The most stable low-energy tautomers are compared to the measured IRMPD spectra to determine which conformer (s) are accessed in the experiments. Additionally, the optimized structures and relative free energies at $298 \mathrm{~K}$ of all of the protonated halouracils are provided in Figure S2 of the Supplementary Information. The relative Gibbs free energies of the six most stable conformations of the $\mathrm{H}^{+}(\mathrm{U})$ and $\mathrm{H}^{+}(\mathrm{xU})$ complexes are compared in Figure $\mathrm{S} 3$.

\section{$H^{+}(5 X U)$}

As mentioned above, the ground-state structure found for $\mathrm{H}^{+}(\mathrm{U})$ and all of the $\mathrm{H}^{+}(5 \mathrm{XU})$ complexes is conformer $\mathbf{A}$ where hydrogen atoms are bound at the $\mathrm{N} 1, \mathrm{O} 2$, and $\mathrm{O} 4$ positions and the $\mathrm{O} 2$ and $\mathrm{O} 4$ hydrogen atoms are oriented toward the neighboring N3 atom (see Figures 4, 5 and 6 and Figures S2, S4, and S5 of the Supplementary Information). The relative stability ordering of the low-energy conformers of 


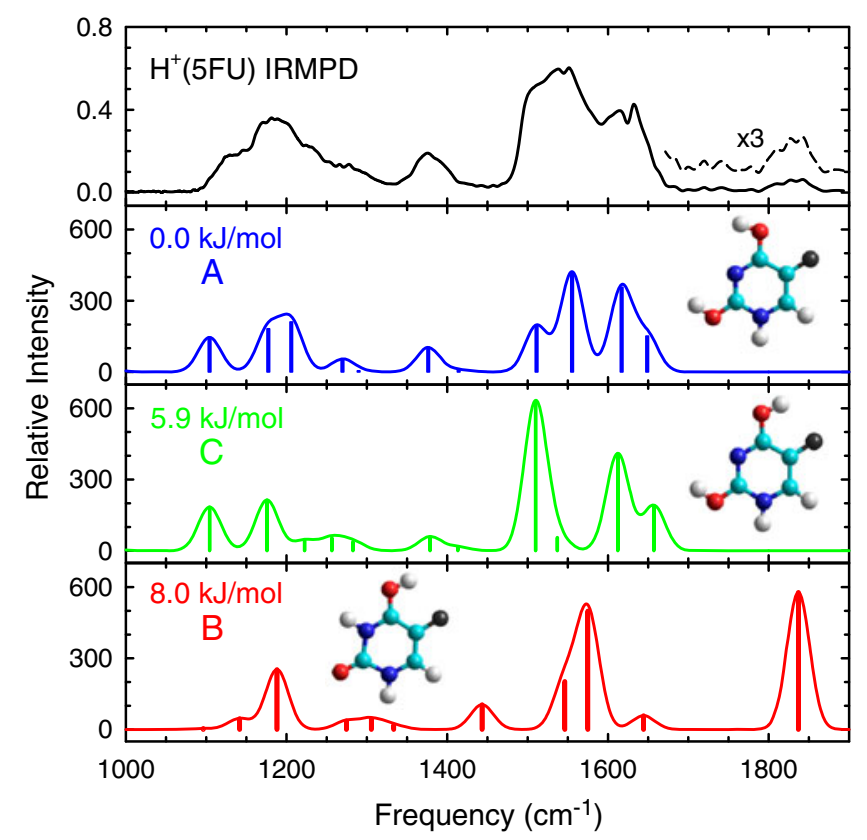

Figure 4. Comparison of the measured IRMPD action spectrum of $\mathrm{H}^{+}(5 \mathrm{FU})$ with linear IR spectra predicted for the three most stable conformers of $\mathrm{H}^{+}(5 \mathrm{FU})$ calculated at the B3LYP/6-311+G(2d,2p)//B3LYP/6-31G* level of theory. Linear IR spectra are shown along with their respective structures and relative Gibbs free energies at $298 \mathrm{~K}$

the $\mathrm{H}^{+}(5 \mathrm{XU})$ complexes is similar to, but differs somewhat from, that found for $\mathrm{H}^{+}(\mathrm{U})$, see Figure $\mathrm{S} 3$ of the Supplementary Information. The $\mathrm{O} 4$ protonated form of the canonical a tautomer in which the proton is oriented toward the $\mathrm{C} 5$ position, conformer $\mathbf{B}$, lies $5.6 \mathrm{~kJ} / \mathrm{mol}$ above the ground-state A conformer for $\mathrm{H}^{+}(\mathrm{U})$, but is destabilized by 5 -fluorosubstitution such that it lies $8.0 \mathrm{~kJ} / \mathrm{mol}$ above the ground-state $\mathbf{A}$ conformer for the $\mathrm{H}^{+}(5 \mathrm{FU})$ complex. Conformer $\mathbf{B}$ become increasingly stable as the size of the halogen substituent increases such that it lies $2.5,0.8$, and $0.2 \mathrm{~kJ} / \mathrm{mol}$ above the ground-state $\mathbf{A}$ conformer for the $\mathrm{H}^{+}(5 \mathrm{ClU}), \mathrm{H}^{+}(5 \mathrm{BrU})$, and $\mathrm{H}^{+}(5 \mathrm{IU})$ complexes, respectively. In contrast, the $\mathrm{O} 4$ rotamer of the ground-state $\mathbf{A}$ conformer, conformer $\mathbf{C}$, lies $16.2 \mathrm{~kJ} / \mathrm{mol}$ higher in free energy for $\mathrm{H}^{+}(\mathrm{U})$, but is stabilized by 5halosubstitution such that it lies $5.9,5.8,5.5$, and $7.2 \mathrm{~kJ} / \mathrm{mol}$ above the ground-state A conformer for the $\mathrm{H}^{+}(5 \mathrm{FU})$, $\mathrm{H}^{+}(5 \mathrm{ClU}), \mathrm{H}^{+}(5 \mathrm{BrU})$, and $\mathrm{H}^{+}(5 \mathrm{IU})$ complexes, respectively. 5-Halosubstitution is found to have the opposite impact on the stability of the $\mathrm{O} 4$ protonated form of the canonical a tautomer in which the proton is oriented toward the N3 position, conformer D. Conformer D of $\mathrm{H}^{+}(\mathrm{U})$ lies $16.5 \mathrm{~kJ} / \mathrm{mol}$ above the ground-state $\mathbf{A}$ conformer, and is destabilized by 5 -halosubstitution such that it lies 28.3, 24.8, 23.9, and $22.4 \mathrm{~kJ} / \mathrm{mol}$ above the $\mathbf{A}$ conformer for the $\mathrm{H}^{+}(5 \mathrm{FU}), \mathrm{H}^{+}(5 \mathrm{ClU}), \mathrm{H}^{+}(5 \mathrm{BrU})$, and $\mathrm{H}^{+}(5 \mathrm{IU})$ complexes, respectively. The relative stabilities of the $\mathrm{O} 2$ rotamers of the ground-state $\mathbf{A}$ conformer, the E conformers, are influenced very little $(<1 \mathrm{~kJ} / \mathrm{mol})$ by the size of the 5-halosubstituent and lie $29.3-29.4 \mathrm{~kJ} / \mathrm{mol}$ above the ground-state A conformer for all of the 5halouracils. In contrast, relative to the $\mathrm{H}^{+}(\mathrm{U})$ complex, the $\mathbf{F}$ conformers formed by $\mathrm{O} 4$ protonation of the minor b tautomers are stabilized by $6.7-11.0 \mathrm{~kJ} / \mathrm{mol}$ for the $\mathrm{H}^{+}(5 \mathrm{FU}), \mathrm{H}^{+}(5 \mathrm{ClU}), \mathrm{H}^{+}(5 \mathrm{BrU})$, and $\mathrm{H}^{+}(5 \mathrm{IU})$ complexes. All other stable conformers computed, including the $\mathrm{O} 2$ protonated forms of the canonical a tautomer, were found to lie at least $10 \mathrm{~kJ} / \mathrm{mol}$ higher in free energy than the $\mathbf{A}-\mathbf{F}$ conformers and are, therefore, unlikely to be experimentally important. Overall, 19, 23, 24, and 25 stable tautomers were calculated for the $\mathrm{H}^{+}(5 \mathrm{FU})$, $\mathrm{H}^{+}(5 \mathrm{ClU}), \mathrm{H}^{+}(5 \mathrm{BrU})$, and $\mathrm{H}^{+}(5 \mathrm{IU})$ complexes, respectively, see Figure S2 of the Supplementary Information.

\section{$H^{+}(6 C l U)$}

As found for $\mathrm{H}^{+}(\mathrm{U})$ and all of the $\mathrm{H}^{+}(5 \mathrm{XU})$ complexes, the ground-state structure of $\mathrm{H}^{+}(6 \mathrm{ClU})$ is conformer A where hydrogen atoms are bound at the $\mathrm{N} 1, \mathrm{O} 2$, and $\mathrm{O} 4$ positions and the $\mathrm{O} 2$ and $\mathrm{O} 4$ hydrogen atoms are oriented toward the neighboring N3 atom, see Figure 6 and Figure S2 of the Supplementary Information. The relative stability ordering of the low-energy conformers of the $\mathrm{H}^{+}(6 \mathrm{ClU})$ complex is also similar to, but again differs somewhat from that found for the $\mathrm{H}^{+}(\mathrm{U})$ and the $\mathrm{H}^{+}(5 \mathrm{XU})$ complexes, see Figure $\mathrm{S} 3$ of the Supplementary Information. Conformer $\mathbf{B}$ is again stabilized by 6-chlorosubstitution, exhibits a relative

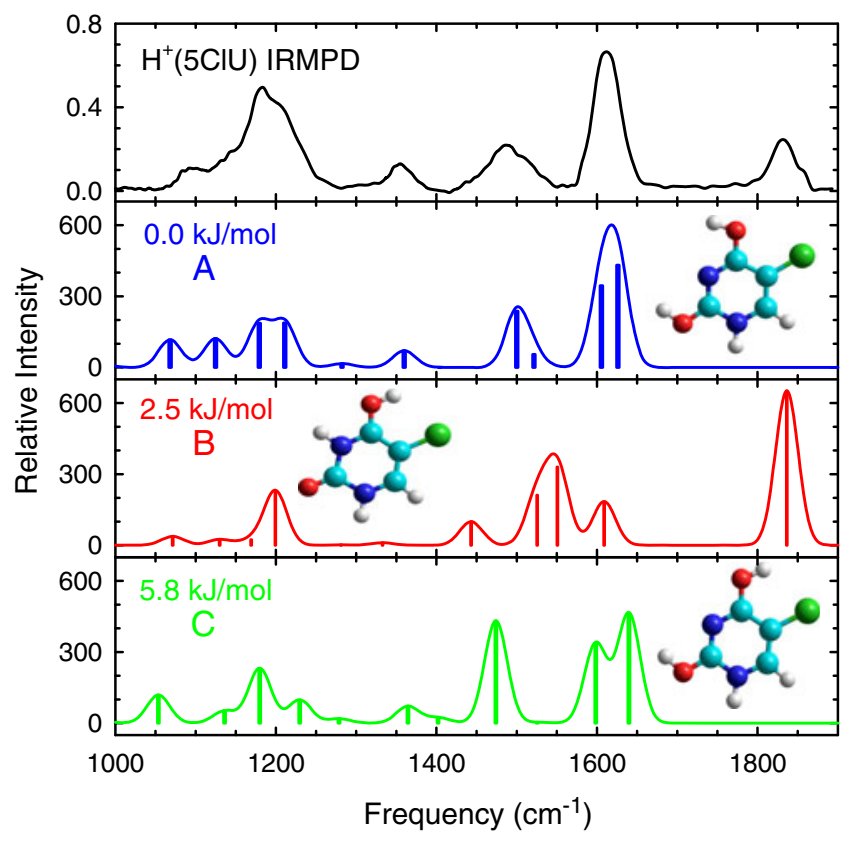

Figure 5. Comparison of the measured IRMPD action spectrum of $\mathrm{H}^{+}(5 \mathrm{CIU})$ with linear IR spectra predicted for the three most stable conformers of $\mathrm{H}^{+}(5 \mathrm{CIU})$ calculated at B3LYP/6-311+G(2d,2p)//B3LYP/6-31G* level of theory. Linear IR spectra are shown along with their respective structures and relative Gibbs free energies at $298 \mathrm{~K}$ 


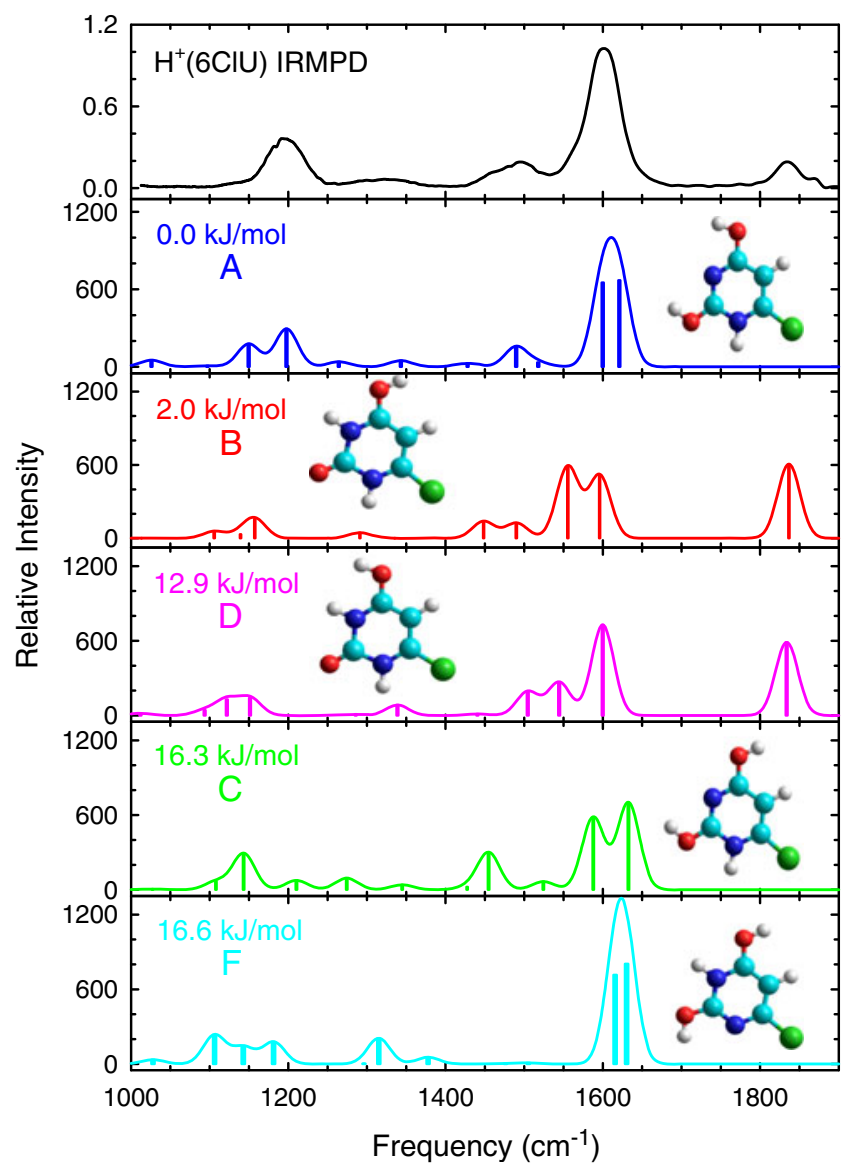

Figure 6. Comparison of the measured IRMPD action spectrum of $\mathrm{H}^{+}(6 \mathrm{CIU})$ with linear $\mathrm{IR}$ spectra predicted for the five most stable conformers of $\mathrm{H}^{+}(6 \mathrm{CIU})$ calculated at the B3LYP/6-311+G(2d,2p)//B3LYP/6-31G* level of theory. Linear IR spectra are shown along with their respective structures and relative Gibbs free energies at $298 \mathrm{~K}$

stability very similar to that found for $\mathrm{H}^{+}(5 \mathrm{ClU})$, and lies 2.0 (versus 2.5) $\mathrm{kJ} / \mathrm{mol}$ above the ground-state A conformer. In contrast to the stabilization found for the 5-halouracils, the $\mathrm{O} 4$ rotamer of the ground-state $\mathbf{A}$ conformer, conformer $\mathbf{C}$, is unaffected by 6-chlorosubstitution and lies $16.3 \mathrm{~kJ} / \mathrm{mol}$ higher in free energy than the ground-state A conformer. 6-Chlorosubstitution produces the opposite effect as 5-halosubstitution on the stability of the D conformer, and is stabilized by $3.6 \mathrm{~kJ} /$ mol for the $\mathrm{H}^{+}(6 \mathrm{ClU})$ complex. As found for the $\mathrm{H}^{+}(5 \mathrm{XU})$ complexes, the relative stability of the $\mathrm{O} 2$ rotamer of the ground-state $\mathbf{A}$ conformer, conformer $\mathbf{E}$, is again influenced very little $(<1 \mathrm{~kJ} / \mathrm{mol})$ by the position of halosubstitution. As found for 5-halosubstitution, 6chlorosubstitution is found to stabilize the $\mathbf{F}$ conformer, but by a greater amount, 14.4 versus $6.7-11.0 \mathrm{~kJ} / \mathrm{mol}$. Conformer $\mathbf{H}$ is found to lie $32.7 \mathrm{~kJ} / \mathrm{mol}$ above the ground-state A conformer versus 47.3-48.6 kJ/mol for $\mathrm{H}^{+}(\mathrm{U})$ and the $\mathrm{H}^{+}(5 \mathrm{XU})$ complexes. All other stable conformers computed except the $\mathrm{O} 4$ rotamer of conformer $\mathbf{F}$, conformer $\mathbf{H}$, were found to lie at least $15 \mathrm{~kJ} / \mathrm{mol}$ higher in free energy than the $\mathbf{A}-\mathbf{F}$ conformers, and are therefore unlikely to be experimentally important. Overall, 24 stable tautomeric conformations were calculated for the $\mathrm{H}^{+}(6 \mathrm{ClU})$ complex (see Figure $\mathrm{S} 2$ of the Supplementary Information).

\section{Discussion}

\section{Comparison of Experimental IRMPD and Theoretical IR spectra of $H^{+}(5 F U)$}

The measured IRMPD action spectrum is compared with the B3LYP/6-31 G* calculated linear IR spectra for the three most stable tautomeric conformations found for the $\mathrm{H}^{+}(5 \mathrm{FU})$ complex in Figure 4. Structures and B3LYP/6-311+G(2d,2p) relative Gibbs free energies at $298 \mathrm{~K}$ are also shown in Figure 4. The ground-state dihydroxy A tautomer provides the best match to the measured IRMPD action spectrum. In particular, the band at $1376 \mathrm{~cm}^{-1}$, and the broad IR absorption feature between $\sim 1470$ and $1670 \mathrm{~cm}^{-1}$ are well matched to the theoretical IR spectrum, where the latter resembles the convolution over the four IR absorption bands at 1511, 1555, 1617 , and $1649 \mathrm{~cm}^{-1}$. Similar behavior is observed in the range between 1075 and $1325 \mathrm{~cm}^{-1}$ as the broad feature in this region appears to be due to a convolution of five IR absorption bands at $1104,1177,1206,1270$, and $1290 \mathrm{~cm}^{-1}$. The band at $1104 \mathrm{~cm}^{-1}$ is obviously red shifted relative to the measured spectrum. Interestingly, the 4-hydroxyl rotamer $\mathbf{C}$ of the ground-state A conformer, which lies $5.9 \mathrm{~kJ} / \mathrm{mol}$ higher in free energy, exhibits several IR absorption peaks that correspond reasonably well to the measured spectrum, although several bands are slightly red or blue shifted. The presence of this minor tautomer would lead to broadening of the measured spectrum as observed, suggesting that the $\mathbf{C}$ conformer may also be present. However, broadening of IR features in IRMPD spectroscopy has been widely observed and may be a result of anharmonic effects as previously described [38]. Therefore, although the measured IRMPD spectrum suggests that the ground state A conformer is dominant, the first excited conformer, $\mathbf{C}$, is likely a minor contributor to the spectrum as well. As discussed, binding of a proton at the $\mathrm{O} 4$ position of the canonical a tautomer of neutral $5 \mathrm{FU}$ results in the protonated $\mathbf{B}$ tautomer, which is $8.0 \mathrm{~kJ} / \mathrm{mol}$ less stable than the ground-state A conformer. The calculated linear IR spectrum for the B tautomer exhibits obvious differences to the measured spectrum. However, when magnified by a factor of three in the carbonyl stretching region, a very weak absorption is observed at $\sim 1825 \mathrm{~cm}^{-1}$, suggesting that a very small population of the $\mathbf{B}$ tautomer is accessed in these experiments. Contributions of the other spectral features associated with the B conformer to the IRMPD action spectrum are difficult to discern as these features would only make very minor contributions to the very broad features observed. The presence of a small ripple in the baseline of the IRMPD 
spectrum near the peak at $1449 \mathrm{~cm}^{-1}$ for the $\mathbf{B}$ tautomer also suggests that the $\mathbf{B}$ conformer is at best present only in very minor abundance.

The IR absorption features observed in the range between 1470 and $1670 \mathrm{~cm}^{-1}$ in the experimental IRMPD action spectrum of $\mathrm{H}^{+}(5 \mathrm{FU})$ can be attributed to four IR absorption bands that appear in the IR spectrum for the ground-state A conformer at $1511,1555,1617$, and $1649 \mathrm{~cm}^{-1}$. The corresponding vibrational modes for these IR bands include intense $\mathrm{C}=\mathrm{C}$ and $\mathrm{C}=\mathrm{N}$ stretching at $1555 \mathrm{~cm}^{-1}$ with a shoulder of medium intensity $\mathrm{C}=\mathrm{O} 4$ stretching at $1510 \mathrm{~cm}^{-1}$, intense $\mathrm{C}=\mathrm{O} 2$ stretching at $1615 \mathrm{~cm}^{-1}$ with a shoulder of strong $\mathrm{C} 5=\mathrm{C} 6$ and $\mathrm{C} 2=\mathrm{N} 3$ stretching at $1650 \mathrm{~cm}^{-1}$. The broad IR absorption features observed in the range between 1075 and $1325 \mathrm{~cm}^{-1}$ correspond to weak in-plane $\mathrm{O} 2 \mathrm{H}, \mathrm{O} 4 \mathrm{H}$, and $\mathrm{C} 6-\mathrm{H}$ bending at $1100 \mathrm{~cm}^{-1}$, medium intensity in-plane $\mathrm{O} 2 \mathrm{H}, \mathrm{N} 1 \mathrm{H}$, and $\mathrm{C} 6-\mathrm{H}$ bending at $1177 \mathrm{~cm}^{-1}, \mathrm{O} 2 \mathrm{H}$ and $\mathrm{O} 4 \mathrm{H}$ in-plane bending at $1206 \mathrm{~cm}^{-1}$, weak in-plane $\mathrm{O} 4 \mathrm{H}$ and $\mathrm{C} 6-\mathrm{H}$ bending and $\mathrm{C}-\mathrm{F}$ stretching at $1270 \mathrm{~cm}^{-1}$, and medium intensity $\mathrm{C} 6-\mathrm{H}$ wagging at $1290 \mathrm{~cm}^{-1}$. Weak N1H in-plane bending is observed at $1376 \mathrm{~cm}^{-1}$.

\section{Comparison of Experimental IRMPD and Theoretical IR Spectra of $\mathrm{H}^{+}(5 \mathrm{ClU})$, $\mathrm{H}^{+}(5 \mathrm{BrU})$, and $\mathrm{H}^{+}(5 \mathrm{IU})$ Complexes}

As previously discussed, the measured IRMPD action spectra for the $\mathrm{H}^{+}(5 \mathrm{ClU}), \mathrm{H}^{+}(5 \mathrm{BrU})$, and $\mathrm{H}^{+}(5 \mathrm{IU})$ complexes are remarkably similar, and thus are examined in parallel here. The measured IRMPD action spectra of the $\mathrm{H}^{+}(5 \mathrm{ClU})$ complex is compared with the B3LYP/6-31G* calculated linear IR spectra for the three most stable tautomeric conformations found in Figure 5, while the analogous figures for the $\mathrm{H}^{+}(5 \mathrm{BrU})$ and $\mathrm{H}^{+}(5 \mathrm{IU})$ complexes are shown in Figures $\mathrm{S} 4$ and $\mathrm{S} 5$ of the Supplementary Information, respectively. Structures and B3LYP/6-311+G(2d,2p) relative Gibbs free energies at $298 \mathrm{~K}$ are also shown in these figures, and for all stable tautomeric conformations computed for the $\mathrm{H}^{+}(5 \mathrm{XU})$ complexes in Figure S2. The calculated linear IR spectra for the ground-state dihydroxy A tautomer provides the best agreement with the experimental spectra for all three complexes. In particular, the bands centered at $\sim 1355,1485$, and $1610 \mathrm{~cm}^{-1}$ is the measured IRMPD spectra closely match the bands at $\sim 1357 \mathrm{~cm}^{-1}$, and two pairs of closely spaced bands at $\sim 1494$ and $1516 \mathrm{~cm}^{-1}$, and $\sim 1604$ and $1623 \mathrm{~cm}^{-1}$ in the calculated linear IR spectra of the A conformers. In both the measured and calculated spectra, the latter features exhibit minor red shifting $\left(5-10 \mathrm{~cm}^{-1}\right)$ as the size of the halogen substituent increases. The broad, intense features observed in the range between 1070 and $1290 \mathrm{~cm}^{-1}$ in the measured IRMPD spectra also correspond reasonably well to four IR absorption bands in the calculated linear IR spectra of the $\mathbf{A}$ conformers that occur at $\sim 1020-1068,1111-1125,1177$, and $1211 \mathrm{~cm}^{-1}$. As found for the $\mathrm{H}^{+}(5 \mathrm{FU})$ complex, the two lowest frequency features in the calculated IR spectra are red shifted relative to the measured IRMPD spectra.
Although the A tautomers appear to be the dominant conformers contributing to the measured IRMPD spectra, contributions from the first excited conformer, B, are apparent as evidenced by the peak associated with the carbonyl stretch at $\sim 1835 \mathrm{~cm}^{-1}$ in the experimental IRMPD spectra. The relative intensity of the carbonyl stretch does not vary significantly across these systems suggesting that the relative stability of the $\mathbf{B}$ conformer is not significantly influenced by its size. This observation is in contrast to theory, which finds that the relative stability of the $\mathbf{B}$ conformers to be increasingly closer to that of the groundstate A conformers as the size of the halogen substituent increases. Thus, it appears that theory may be over estimating the influence of the size of the halogen substituent on the stability of the $\mathbf{B}$ conformer. Other vibrational modes exhibited by the $\mathbf{B}$ tautomers including IR absorption features occurring at $\sim 1442,1525$, and $1545 \mathrm{~cm}^{-1}$ lead to slight broadening of the IR absorption bands near $\sim 1485 \mathrm{~cm}^{-1}$ in the measured spectra. The shape of the IRMPD features in the range from 1070 to $1290 \mathrm{~cm}^{-1}$ are sufficiently broadened such that minor contributions from the $\mathbf{B}$ conformers are difficult to decipher, although the shape of these bands suggest that the peaks at $\sim 1200 \mathrm{~cm}^{-1}$ in the calculated IR spectra of the $\mathbf{B}$ tautomers contribute to these features.

The calculated linear IR spectra for the $\mathbf{C}$ rotamers of $\mathbf{A}$ exhibit obvious differences to the measured IRMPD spectra. The IR absorption peaks for the $\mathbf{C}$ tautomer at $\sim 1636 \mathrm{~cm}^{-1}$ are absent in the measured spectrum, and the peaks at $~ 1470$ and $1597 \mathrm{~cm}^{-1}$ are red shifted as compared to the measured spectrum. The measured IRMPD features in the range from 1070 to $1290 \mathrm{~cm}^{-1}$ are again sufficiently broadened that minor contributions from the IR bands at $\sim 1130,1180$, and $1230 \mathrm{~cm}^{-1}$ of the $\mathbf{C}$ tautomers cannot be deciphered. The bands at $\sim 1011-53 \mathrm{~cm}^{-1}$ for the $\mathbf{C}$ tautomer do not appear in the experimental IRMPD spectrum, and these features are further red-shifted compared with the analogous features in the spectra of conformers $\mathbf{A}$ and $\mathbf{B}$, again suggesting that if present, the $\mathbf{C}$ tautomer is a very minor contributor to the experimental IRMPD spectra of these $\mathrm{H}^{+}(5 \mathrm{XU})$ complexes.

Comparison of the measured IRMPD spectra with the linear IR spectra for the $\mathbf{A}$ and $\mathbf{B}$ conformers suggests that the broad features in the region between 1070 and 1290 $\mathrm{cm}^{-1}$ correspond to $\mathrm{O} 2 \mathrm{H}$ and $\mathrm{C} 6-\mathrm{H}$ in-plane bending and $\mathrm{N} 3-\mathrm{C} 4-\mathrm{C} 5$ bending at $1020-68 \mathrm{~cm}^{-1}, \mathrm{O} 2 \mathrm{H}, \mathrm{O} 4 \mathrm{H}$, and $\mathrm{N} 1 \mathrm{H}$ in-plane bending at $1111-1125 \mathrm{~cm}^{-1}$, medium intensity $\mathrm{O} 2 \mathrm{H}$ and $\mathrm{N} 1 \mathrm{H}$ in-plane bending at $1177 \mathrm{~cm}^{-1}$, medium intensity $\mathrm{O} 4 \mathrm{H}$ in-plane bending at $1211 \mathrm{~cm}^{-1}$, and also weak intensity in-plane $\mathrm{C} 6-\mathrm{H}$ bending modes are observed at $1282 \mathrm{~cm}^{-1}$. The weak bands centered at $\sim 1355 \mathrm{~cm}^{-1}$ in the measured IRMPD spectra correspond to $\mathrm{N} 1 \mathrm{H}$ and $\mathrm{O} 4 \mathrm{H}$ in-plane bending and asymmetric ring stretching. The very broad weak bands centered at $\sim 1485 \mathrm{~cm}^{-1}$ are attributed to $\mathrm{C} 6-\mathrm{H}$ in-plane bending, medium intensity $\mathrm{C}-\mathrm{O} 4 \mathrm{H}$ stretching, and weak $\mathrm{C} 5-\mathrm{Cl}$ stretching. The most intense features observed for these complexes can be attributed to strong 
$\mathrm{C}-\mathrm{O} 2 \mathrm{H}$ and asymmetric ring stretching and $\mathrm{N} 1 \mathrm{H}$ in-plane bending at $\sim 1610 \mathrm{~cm}^{-1}$ and to $\mathrm{C} 2=\mathrm{N} 3$ and $\mathrm{C} 5=\mathrm{C} 6$, and $\mathrm{N} 1 \mathrm{H}$ in-plane bending at $1622-1626 \mathrm{~cm}^{-1}$. The bands at $\sim 1835 \mathrm{~cm}^{-1}$ in the measured IRMPD spectra clearly arise from carbonyl stretching exhibited only by the $\mathbf{B}$ tautomer.

\section{Comparison of Experimental and Theoretical IR Spectra of $H^{+}$(6ClU)}

The measured IRMPD action spectrum is compared to the B3LYP/6-31G* calculated linear IR spectra for the five most stable tautomeric conformations found for the $\mathrm{H}^{+}(6 \mathrm{ClU})$ complex in Figure 6. The structures and B3LYP/6-311+G(2d,2p) relative Gibbs free energies at $298 \mathrm{~K}$ are also shown in Figure 6. The ground-state dihydroxy A conformer provides the best match to the IRMPD action spectrum although features in the range 1150 to $1250 \mathrm{~cm}^{-1}$ are slightly red shifted in the calculated spectrum. Although broadened, the intense IR absorption feature in the range from 1525 to $1650 \mathrm{~cm}^{-1}$ closely resembles coupling of the calculated bands at 1600 and $1620 \mathrm{~cm}^{-1}$. Contributions from the calculated band at $1490 \mathrm{~cm}^{-1}$ are evident in the broad absorption peak occurring in the range from 1425 to $1525 \mathrm{~cm}^{-1}$ in the measured spectrum. Calculated bands at 1150 and $1198 \mathrm{~cm}^{-1}$, while slightly red shifted, match the measured feature in the range from 1150 to $1250 \mathrm{~cm}^{-1}$. Because the ground-state tautomer does not contain a free carbonyl group, a low intensity band occurring at $\sim 1835 \mathrm{~cm}^{-1}$ in the measured spectrum indicates contributions from one or more tautomer(s) other than the ground-state. The calculated band at $1835 \mathrm{~cm}^{-1}$ for the first excited tautomer, B, matches the band occurring in the measured spectrum well. Other features calculated for the first excited conformer do not obviously resemble features observed in the measured spectrum. However, evidence that these calculated features contribute to absorption in the IRMPD action spectrum is indicated by sufficient broadening of the measured features. For example, calculated bands at 1554 and $1599 \mathrm{~cm}^{-1}$ may contribute to the broad shoulder on the measured feature centered at $\sim 1600 \mathrm{~cm}^{-1}$. In the band observed at $\sim 1495$ $\mathrm{cm}^{-1}$, two calculated bands at 1449 and $1495 \mathrm{~cm}^{-1}$ seem to lead to severe band broadening. Similarly, the calculated band at $1153 \mathrm{~cm}^{-1}$ may broaden the measured feature occurring in the region between 1150 and $1250 \mathrm{~cm}^{-1}$ in the IRMPD action spectrum. These comparisons suggest that the first excited tautomer, $\mathbf{B}$, is present in the measured IRMPD action spectrum as a minor contributor. The second excited tautomer, $\mathbf{D}$, also exhibits a carbonyl stretching peak that could explain the presence of the band at $\sim 1825 \mathrm{~cm}^{-1}$ in the measured IRMPD spectrum. Contributions from other calculated bands for the D tautomer at 1502, 1548, and $1600 \mathrm{~cm}^{-1}$ can also not be ruled out as a result of significant broadening of the measured features in this region. Calculated bands at 1151, 1097 , and $1120 \mathrm{~cm}^{-1}$ are not apparent in the measured spectrum. Based on these correlations, the presence of the D tautomer as a minor contributor cannot be ruled out, but if present it is only a very minor contributor to the measured IRMPD spectrum. The third excited conformer, C, does not closely resemble or obviously contribute to the measured IRMPD spectrum. If tautomer $\mathrm{C}$ were present in the experiments, the band calculated at $1640 \mathrm{~cm}^{-1}$ would likely lead to more severe broadening on the blue side of the feature centered at $\sim 1600 \mathrm{~cm}^{-1}$. Because the band at $1590 \mathrm{~cm}^{-1}$ for the C tautomer occurs near the middle of the broad absorption feature observed in the measured spectrum, its presence or absence cannot be definitively determined. While the calculated band at $1452 \mathrm{~cm}^{-1}$ may lead to broadening of the measured feature near $\sim 1495 \mathrm{~cm}^{-1}$, the calculated band at $1147 \mathrm{~cm}^{-1}$ is absent in the IRMPD spectrum. Minor contributions from the C tautomer cannot be definitely ruled out. However, it is unlikely that this tautomer is present in measurable abundance in these experiments. Convolution of the two bands at 1615 and $1635 \mathrm{~cm}^{-1}$ for the fourth excited tautomer, $\mathbf{F}$, resembles the measured IR feature occurring at $\sim 1600 \mathrm{~cm}^{-1}$. However, the calculated feature for the $\mathbf{F}$ tautomer is moderately blue shifted relative to the measured feature. Thus, more severe peak broadening would be expected if the calculated feature were contributing to the measured spectrum. Overlapping bands at 1148 and $1185 \mathrm{~cm}^{-1}$ in the theoretical spectrum for the $\mathbf{F}$ tautomer do not obviously contribute to the measured spectrum. The calculated band at $1102 \mathrm{~cm}^{-1}$ is either absent or severely red shifted in the measured spectrum, which in the latter case would lead to it being indistinguishable as a result of broadening. These relationships suggest that the $\mathbf{F}$ tautomer is most likely not accessed in these experiments.

Comparison of the measured IRMPD spectrum and the linear IR spectrum of the ground-state $\mathbf{A}$ conformer of $\mathrm{H}^{+}(6 \mathrm{ClU})$ suggest that the intense IR feature occurring in the range from 1550 to $1650 \mathrm{~cm}^{-1}$ corresponds $\mathrm{N} 1 \mathrm{H}$ in-plane bending with a shoulder of $\mathrm{C}-\mathrm{O} 2 \mathrm{H}$ and symmetric ring stretching. The weak and very broad peak centered at $1490 \mathrm{~cm}^{-1}$ is due to $\mathrm{N} 1 \mathrm{H}$ in-plane bending and $\mathrm{C}-\mathrm{O} 4 \mathrm{H}$ stretching. The broad IR absorption feature occurring in the range from 1150 to $1250 \mathrm{~cm}^{-1}$ is due to $\mathrm{O} 2 \mathrm{H}$ and $\mathrm{O} 4 \mathrm{H}$ in-plane bending. Again, the weak absorption at $1835 \mathrm{~cm}^{-1}$ corresponds to $\mathrm{O} 2$ carbonyl stretching arising from the $\mathbf{B}$ conformer.

\section{Comparison of Proton and Sodium Cation Binding to Uracil and Modified Uracils}

In parallel studies of the protonated and sodium cationized forms of uracil and thioketo- and methylthioketouracils [15, 17], we determined that both protonation and sodium cationization result in stabilization of minor tautomers of these nucleobases. The effects of protonation are more significant than that of sodium cationization and result in preferential stabilization of minor tautomers [15]. In contrast, the ground-state conformations of the sodium cationized complexes involve the canonical tautomer of the nucleobase. However, there is evidence for minor tautomers 
of the sodium cationized complexes in several cases [17]. The present results also provide evidence for the preferential stabilization of minor tautomers upon protonation of the halouracils. The effects of sodium cationization on the tautomeric conformations of the halouracils are currently under investigation in our laboratory. Preliminary results suggest that the effects of sodium cationization are less dramatic than the effects of protonation of the halouracils. Sodium cationization stabilizes minor tautomers, but the ground-state conformations of these complexes involve the canonical tautomers of the nucleobase. Combined, these results suggest that protonation is likely to induce tautomerization of other nucleobases, whereas weaker noncovalent interactions with sodium cations are less likely to induce tautomerization.

\section{Conclusions}

IRMPD action spectra of the protonated halouracils have been measured in the range from $\sim 1000$ to $1900 \mathrm{~cm}^{-1}$. To determine the various tautomeric conformations accessed in these experiments, measured spectra are compared with linear theoretical IR spectra calculated at the B3LYP/6-31G* level of theory. Ground-state structures predicted for the protonated halouracils, $\mathrm{H}^{+}(5 \mathrm{FU}), \mathrm{H}^{+}(5 \mathrm{ClU}), \mathrm{H}^{+}(5 \mathrm{BrU})$, $\mathrm{H}^{+}(5 \mathrm{IU})$, and $\mathrm{H}^{+}(6 \mathrm{ClU})$ confirm that protonation preferentially stabilizes alternative, noncanonical tautomers of the halouracils where both of the keto functionalities are converted to hydroxyl groups. Therefore, the findings of Salpin et al. [10] and Nei et al. [15] that noncanonical tautomers of thioketo- and methylthioketouracils, respectively, are stabilized by proton binding hold true for halouracils as well. Owing to increased stability, noncanonical tautomers have a greater likelihood of being present in a distribution of several other conformers. Consequently, because incorporation of noncanonical nucleobase conformers can interfere with nucleic acid synthesis [26], the presence of proton-stabilized noncanonical halouracil tautomers would likely result in an increased probability that nucleic acid synthesis is disrupted.

\section{Acknowledgments}

The authors acknowledge financial support for this work by the National Science Foundation, grants PIRE-0730072 and CHE-0911191. The authors thank WSU C\&IT for computer time. This work is part of the research program of FOM, which is financially supported by the Netherlandse Organisatie voor Wetenschappelijk Onderzoek (NWO). The skillful assistance of the FELIX staff is gratefully acknowledged.

\section{References}

1. Watson, J.D., Crick, F.H.: Genetic implications of the structure of deoxyribonucleic acid. Nature 171, 964-767 (1953)

2. Sowers, L.C., Shaw, B.R., Veigl, M.L., Sedwick, W.D.: DNA base modification: ionized base pairs and mutagenesis. Mutat. Res. 177, 201-218 (1987)
3. Lowdin, P.O.: Proton tunneling in DNA and its biological applications. Rev. Mod. Phys. 35, 724-732 (1963)

4. Kool, E.T.: Hydrogen bonding, base stacking, and steric effects in DNA replication. Annu. Rev. Biophys. Biomol. Struct. 30, 1-22 (2001)

5. Topal, M.D., Fresco, J.R.: Complementary base pairing and the origin of substitution mutations. Nature 263, 285-289 (1976)

6. Freese, E.: The specific mutagenic effect of base analogues on Phage T4. J. Mol. Biol. 1, 87-105 (1959)

7. Katritzky, A.R., Waring, A.J.: Tautomeric azines, I. Tautomerism of 1methyluracil and 5-bromo-1-methyluracil. J. Chem. Soc. 1540-1544 (1962)

8. Fresco, J.R., Broitman, S., Lane, A.E.: Base pair mismatching and nearest-neighbor effects in transition mutations. In: Alberts, B., Fox, C.F. (Eds.) Mechanistic studies of DNA replication and genetic recombination. Academic Press: New York, pp. 753-768 (1980)

9. Singer, B., Kusmierek, J.T.: Chemical mutagenesis. Annu. Rev. Biochem. 51, 655-693 (1982)

10. Salpin, J.-Y., Guillaumont, S., Tortajada, J., MacAleese, L., Lemaire, J., Maître, P.: Infrared spectra of protonated uracil, thymine, and cytosine. Chem. Phys. Chem. 8, 2235-2244 (2007)

11. Modrich, P., Lahue, R.: Mismatch repair in replication fidelity, genetic recombination and cancer biology. Annu. Rev. Biochem. 65, 101-134 (1996)

12. Stanbridge, E.J.: Human tumor suppressor genes. Annu. Rev. Genet. 24, 615-657 (1990)

13. Fearon, E.R., Vogelstein, B.: A genetic model for colorectal tumorigenesis. Cell 61, 759-767 (1990)

14. Bishop, J.M.: Molecular themes in oncogenesis. Cell 64, 235-248 (1991)

15. Nei, Y.-w., Akinyemi, T.E., Steill, J.D., Oomens, J., Rodgers, M. T.: Infrared multiple photon dissociation action spectroscopy of protonated uracil and thiouracils: effects of thio-keto substitution on gas-phase conformation. Int. J. Mass Spectrom. 297, 139-151 (2010)

16. Yang, Z., Rodgers, M.T.: Influence of halogenation on the properties of uracil and its noncovalent interactions with alkali metal ions. Threshold collision-induced dissociation and theoretical studies. J. Am. Chem. Soc. 126, 16217-16226 (2004)

17. Nei, Y.-w., Akinyemi, T.E., Kaczan, C.M., Steill, J.D., Oomens, J., Rodgers, M.T.: Infrared multiple photon dissociation action spectroscopy of sodiated uracil and thiouracils: Effects of thio-keto substitution on gas-phase conformation. Int. J. Mass Spectrom. 308, 191-202 (2011)

18. Wang, H.-p., Xu, W.-g., Zhang, H.-x.: Theoretical studies on structure and electron affinity of 5- and 6- halouracils. Chem. Res. Chinese U. 25, 388-396 (2009)

19. Leszczynski, J.: Tautomerism of uracil: the final chapter? Fourth-order electron correlation contributions to the relative energies of tautomers. J. Phys. Chem. 96, 1649-1653 (1992)

20. Bakker, J.M., Sinha, R.K., Besson, T., Brugnara, M., Tosi, P., Salpin, J.-Y., Maitre, P.: Direct evidence for tautomerization of the uracil moiety within the Pb2+/uridine-5'-monophosphate complex: a combined tandem mass spectrometry and IRMPD study. J. Phys. Chem. A 112, 12393-12400 (2009)

21. Orozco, M., Hernández, B., Luque, F.J.: Tautomerism of 1-methyl derivatives of uracil, thymine, and 5-bromouracil. Is tautomerism the basis for the mutagenicity of 5-bromouridine? J. Phys. Chem. B 102, 5228-5233 (1998)

22. Scanlan, M.J., Hillier, I.H.: An ab initio study of tautomerism of uracil, thymine, 5-fluorouracil, and cytosine. J. Am. Chem. Soc. 106, 37373745 (1984)

23. Tian, S.X., Zhang, C.F., Zhang, Z.J., Chen, X.J., Xu, K.Z.: How many uracil tautomers are there? Density functional studies of stability ordering of tautomers. Chem. Phys. Lett. 242, 217-225 (1999)

24. Feyer, V., Plekan, O., Richter, R., Coreno, M., V.-llosera, G., Prince, K.C., Trofimov, A.B., Zaytseva, I.L., Moskovskaya, T.E., Gromov, E.V., Schirmer. J.: Tautomerism in cytosine and uracil: an experimental and theoretical core level spectroscopic study. J. Phys. Chem. A 113, 5736-5742 (2009)

25. Hu, X., Li, H., Zhang, L., Han, S.: Tautomerism of uracil and 5bromouracil in a microcosmic environment with water and metal ions. What roles do metal ions play? J. Phys. Chem. B 111, 9347-9354 (2007)

26. Brown, D.J.; Evans, R.F.; Cowden, W.B.; Fenn M.D. In: The Pyrimidines; Chemistry of Heterocyclic Compounds A Series of Monographs 52; John Wiley and Sons: New York, 1994 
27. Pérez, A., Tuckerman, M., Hjalmarson, H.P., von Lillienfeld, O.A.: Enol tautomers of Watson-Crick base pair models are metastable because of nuclear quantum effects. J. Am. Chem. Soc. 132, 11510 11515 (2010)

28. Heidelberger, C., Chaudhuri, N.K., Danneberg, P., Mooren, D., Griesbach, L., Duschinsky, R., Schnitzer, R.J., Pleven, E., Scheiner, J.: Fluorinated pyridimines: a new class of tumor-inhibitory compounds. Nature 179, 663-666 (1957)

29. Bernhard, H., J.-Arand, E., Bernhard, G., Heike, M., Klein, O., Riemann, J.F., Meyer zum Büschenfelde, K.H., Dippold, W., Knuth, A.: Treatment of advanced pancreatic cancer with 5-fluorouracil, folinic acid and interferon alpha-2A: results of a phase II trial. Br. J. Cancer. 71, 102-105 (1995)

30. Neoptolemos, J.P., Stocken, D.D., Smith, C.T., Bassi, C., Ghaneh, P., Owen, E., Moore, M., Padbury, R., Doi, R., Smith, D., Buchler, M.W.: Adjuvant 5-fluorouracil and folinic acid versus observation for pancreatic cancer: composite data from the ESPAC-1 and -3(v1) trials. Br. J. Cancer. 100, 246-250 (2009)

31. Meyerhardt, J.A., Mayer, R.J., Engl, N.: Systematic therapy for colorectal cancer. N. Engl. J. Med. 352, 476-487 (2005)

32. Noordhuis, P., Holwerda, U., van der Wilt, C.L., van Groeningen, C.J., Smid, K., Meijer, S., Pinedo, H.M., Peter, G.J.: 5-Fluorouracil incorporation into RNA and DNA in relation to thymidylate synthase inhibition of human colorectal cancers. Ann. Oncol. 15, 1025-1032 (2004)

33. Mauro, D.J., De Riel, J.K., Tallarida, R.J., Sirover, M.A.: Mechanisms of excision of 5-fluorouracil by uracil DNA glycosylase in normal human cells. Mol. Pharmacol. 43, 854-857 (1993)

34. Valle, J.J., Eyler, J.R., Oomens, J., Moore, D.T., van der Meer, A.F.G., von Helden, G., Meijer, G., Hendrickson, C.L., Marshall, A.G., Blakney, G.T.: Free electron laser-Fourier transform ion cyclotron resonance mass spectrometry facility for obtaining infrared multiphoton spectra of gaseous ions. Rev. Sci. Instrum. 76, 023103-023110 (2005)

35. Polfer, N.C., Oomens, J., Moore, D.T., von Helden, G., Meijer, G., Dunbar, R.C.: Infrared spectroscopy of phenylalanine $\mathrm{Ag}(\mathrm{I})$ and $\mathrm{Zn}(\mathrm{II})$ complexes in the gas phase. J. Am. Chem. Soc. 128, 517-525 (2006)
36. Polfer, N.C., Oomens, J.: Reaction products in mass spectrometry elucidated by infrared spectroscopy. Phys. Chem. Chem. Phys. 9, 38043817 (2007)

37. Oepts, D., van der Meer, A.F.G., van Amersfoort, P.W.: The freeelectron laser user facility FELIX. Infrared Phys. Technol. 36, 297-308 (1995)

38. Oomens, J., Sartakov, B.G., Meijer, G., von Helden, G.: Gas-phase infrared multiple photon dissociation spectroscopy of mass-selected molecular ions. Int. J. Mass Spectrom. 254, 1-19 (2006)

39. Armentrout, P.B., Rodgers, M.T., Oomens, J., Steill, J.D.: Infrared multiphoton dissociation spectroscopy of cationized serine: Effects of alkali-metal cation size on gas-phase conformation. J. Phys. Chem. A 112, 2248-2257 (2008)

40. Rodgers, M.T., Armentrout, P.B., Oomens, J., Steill, J.D.: Infrared multiphoton dissociation spectroscopy of cationized threonine: Effects of alkali-metal cation size on gas-phase conformation. J. Phys. Chem. A. 112, 2258-2267 (2008)

41. Frisch, M.J.; Trucks, G.W.; Schlegel, H.B.; Scuseria, G.E.; Robb, M.A.; Cheeseman, J.R.; Montgomery, J.A. Jr.; Vreven, T.; Kudin, K. N.; Burant, J. C.; Millam, J. M.; Iyengar, S. S.; Tomasi, J.; Barone, V.; Mennucci, B.; Cossi, M.; Scalmani, G.; Rega, N.; Petersson, G.A.; Nakatsuji, H.; Hada, M.; Ehara, M.; Toyota, K.; Fukuda, R.; Hasegawa, J.; Ishida, M.; Nakajima, T.; Honda, Y.; Kitao, O.; Nakai, H.; Klene, M.; Li, X.; Knox, J. E.; Hratchian, H. P.; Cross, J. B.; Bakken, V.; Adamo, C.; Jaramillo, J.; Gomperts, R.; Stratmann, R. E.; Yazyev, O.; Austin, A. J.; Cammi, R.; Pomeli, C.; Ochterski, J. W.; Ayala, P. Y.; Morokuma, K.; Voth, G. A.; Salvador, P.; Dannenberg, J. J.; Zakrzewski, V. G.; Dapprich, S.; Daniels, A. D.; Strain, M. C.; Farkas, O.; Malick, D. K.; Rabuck, A. D.; Raghavachari, K.; Foresman, J. B.; Ortiz, J.V.; Cui, Q.; Baboul, A. G.; Clifford, S.; Cioslowski, J.; Stefanov, B. B.; Liu, G.; Liashenko, A.; Piskorz, P.; Komaromi, I.; Martin, R. L.; Fox, D. J.; Keith, T.; Al-Laham, M. A.; Peng, C. Y.; Nanayakkara, A.; Challacombe, M.; Gill, P. M. W.; Johnson, B.; Chen, W.; Wong, M. W.; Gonzalez, C.; Pople, J. A. Gaussian 09, Revision A.02. Gaussian, Inc.: Wallingford CT, 2004 